\title{
Descentralização e regionalização: dinâmica e condicionantes da implantação do Pacto pela Saúde no Brasil
}

\author{
Decentralization and regionalization: dynamics and conditioning \\ factors for the implementation of the Health Pact in Brazil
}

Luciana Dias de Lima ${ }^{1}$

Lúcia F. N . de Queiroz ${ }^{2}$

Cristiani Vieira M achado ${ }^{1}$

Ana Luiza d'Á vila Viana ${ }^{3}$
${ }^{1}$ Departamento de

Administração e

Planejamento em Saúde,

Escola Nacional de Saúde

Pública Sergio Arouca,

Fundação Oswaldo Cruz.

RuaLeopoldo Bulhões

1480/Prédio da EN SP/sala

715, M anguinhos. 21041-

210 Rio de Janeiro RJ.

luciana@ensp.fiocruz.br

${ }^{2}$ Departamento deCiênciae

Tecnologia, Secretaria de

Ciência, Tecnologiae

Insumos Estratégicos,

Ministério da Saúde.

${ }^{3}$ Departamento de M edicina

Preventiva, Faculdade de

M edicina, Universidade de

São Paulo.
Abstract Decentralization and regionalization represent constitutional guidelines for the organization of the U nified $\mathrm{H}$ ealth System, which in the last 20 years has required the adoption of mechanisms to coordinate and accommodate federative tensions in Brazil's healthcare sector. This paper analyzes the national implementation of the $\mathrm{H}$ ealth Pact between 2006 and 2010 involving a strategy that reconfigures intergovernmental relations in the sector. The study involved the analysis of documents, official data and interviews with federal, state and municipal managers in the Brazilian states. The content of the national proposal is initially discussed, including its implications for health policy. The different rhythms and degrees of implementation of the Health Pact are then reviewed, with respect to adherence by states and municipalities and the formation of Regional $M$ anagement Boards. Lastly, the conditioning factors for the multiplicity of experiences observed in the country are identified and the challenges facing progress toward a decentralized and regionalized health system in Brazil are discussed.

Key words Decentralization, Regional health planning, Health policy, Unified Health System, Federalism, $\mathrm{H}$ ealth pact
Resumo A descentralização e a regionalização representam diretrizes constitucionais de organização do Sistema Ú nico de Saúde queexi giram, nos últimos vinte anos, a adoção de mecanismos de coordenação e acomodação das ten sões federativas em saúde no Brasil. 0 artigo analisa a implantação nacional do Pacto pela Saúde, estratégia que reconfigura as relações intergovernamentais no setor, de 2006 a 2010. A pesqui sa envolveu análise de documentos, de dados oficiaise realização de entrevistas com dirigentes federais, estaduais e munici pais nos estados brasileiros. Inicialmente discorre-se sobre o conteúdo da proposta nacional e seus desdobramentos para a política de saúde. A seguir, analisam-se os diferentes ritmose graus deimplantação do Pacto pela Saúde, no que concerne à adesão dos estados e municípios e à conformaação de Colegiados de Gestão Regional. Por fim, sistematizam-se os fatores condicionantes da multipli cidade das experiências observadas no país e di scutem-se os desafi os para o avanço da descentralização e da regionalização no sistema de saúde brasileiro.

Palavras-chave Descentralização, Regionalização, Política de saúde, Sistema Ú nico de Saúde, Federalismo, Pacto pela saúde 


\section{Introdução}

A Constituição Federal de $1988^{1}$ ea Lei O rgânica da Saúde de $1990^{2}$ estabelecem a descentralização e a regionalização como princípios norteadores dos processos de organização político-territorial do Sistema Ú nico de Saúde (SUS).

A descentralização redefine responsabilidades entre os entes governamentais e reforça a importância dos executivos subnacionais na condução da política de saúde. Ela envolve a transferência de poder decisório, da gestão de prestadores e de recursos financeiros, antes concentrados na esfera federal para estados e, principalmente, para os municípios. Informado por matrizes ideológicas e experiências diversas ${ }^{3,4}$, o fortalecimento desses governos se justifica como forma de promover a democratização, melhorar a eficiência e os mecanismos de accountability nas políticas públicas, respeitando o desenho federativo eatendendo aos interesses territoriais da nação ${ }^{5}$.

Entretanto, frente à concentração geográfica deserviços demaior complexidade, às diferenças deportepopulacional econdições político-institucionais dos entes federativos no Brasil, há necessidade de conformação de arranjos regionalizados de atenção à saúde que não se restringem aos seus limites administrativos, sendo a interdependência entre os governos bastante significativa ${ }^{6,7}$. Admitindo múltiplos partícipes, a regionalização na saúdeéum processo político, condicionado pelas relações estabelecidas entre diferentes atores sociais (governos, organizações, cidadãos) no espaço geográfico ${ }^{8,9}$. Inclui, ainda, 0 desenvolvimento de estratégias e instrumentos de planejamento, integração, gestão, regulação e financiamento de uma rede de ações e serviços no território.

Por outro lado, ressaltam-se as especificidades da implantação de políticas públicas em contextos federativos. Sob regimes democráticos, 0 desenho institucional das federações garante a repartição do poder do Estado, de modo que diferentes esferas de governo possam participar do processo político e defender seus direitos originários ${ }^{10}$. Nesses casos, a implantação de sistemas nacionais e universais como o SUS supõe o entendimento entre autoridades políticas dotadas de vários tipos de poder elegitimidade, que agregam e empregam recursos diversos. Observam-se relações de cooperação e competição, vetos e decisões conjuntas entre atores com projetos políticos frequentemente divergentes ${ }^{11}$.

Estudos sugerem que a política de saúde brasileira desenvolveu mecanismos próprios de in- dução e coordenação ${ }^{12-14}$, permitindo a acomodação das tensões federativas nos processos de descentralização e regionalização do SUS. A regulação desses processos foi realizada pelo $\mathrm{Mi}$ nistério da Saúde, por meio da normatização, consubstanciada pela edição anual de dezenas de portarias, em geral, associadas a mecanismos financeiros ${ }^{15}$.

De caráter transitório, estas normas foram sendo complementadas e sucessivamente substituídas, apresentando diferenças, mas também elementos de continuidade entre $\mathrm{si}^{16,17}$, sendo marcadas por intenso debate envolvendo as três esferas de governo eo Conselho N acional deSaúde. Nos anos 90, foram publicadas quatro Normas Operacionais Básicas (N OB) e, em 2001, a Norma Operacional da Assistência à Saúde (NOAS, reformulada em nova versão em 2002). A partir de 2006, foi instituído o Pacto pela Saúde, conformado pelo Pacto de Gestão, Pacto pela Vida e Pacto em D efesa do SU S ${ }^{18,19}$.

No plano nacional, os contextos históricose político-institucionais relacionados à formulação e à implementação das políticas federais desenhadas ao longo dos anos 90 e 2000 tensionam eatualizam procedimentos em vigor e permitem identificar diferentesciclos da descentral ização no SUS, com menor ou maior ênfase na regionalização ${ }^{8}$. M as épreciso reconhecer a complexidade e a diversidade desses fenômenos no Brasil. As múltiplas realidades territoriais existentes e a importância adquirida pelas instâncias estaduais emunicipais na condução da política de saúde, influenciam os processos de descentralização e regionalização do SUS nos estados brasileiros.

Partindo desses pressupostos, a presenteinvestigação tem como objeto de análisea implantação do Pacto pela Saúde no período de 2006 a 2010, considerando os diferentes ritmos e graus de adesão dos governos subnacionais ao Pacto e a influência de contextos específicos nestes processos.

I nicialmente, discorre-se sobrea formulação e o conteúdo da proposta, destacando-se seus desdobramentos para as relações entre os governos nos processos de organização políticoterritorial do SUS. Em seguida, apresentam-se a metodologia do estudo e seus resultados em dois eixos principais. Em um primeiro eixo, enfatizase a dinâmica da implantação do Pacto, no que se refere à adoção pelos governos estaduais e municipais das estratégias e instrumentos preconizados pela política federal; em um segundo, sistematizam-se alguns fatores condicionantes destes processos, identificados a partir de fontes primárias de pesquisa, que ajudam na configu- 
ração dos contextos e na compreensão da multiplicidade das experiências investigadas. N as conclusões, à luz dos resultados e da discussão anterior, destacam-se al guns limites e desafios para o avanço da descentralização e da regionalização do SUS evocados pelo Pacto.

\section{O Pacto pela Saúde}

0 debate que culminou na publicação das diretrizes do Pacto pela Saúdeem 2006 foi desencadeado a partir de $2003 \mathrm{com}$ a entrada de novos dirigentes no M inistério da Saúde, que identificaram a necessidade de mu danças nas formas de relacionamento estabelecidas entre as esferas de governo na política de saúde. Havia, à época, uma forte crítica ao modelo de condução federal da descentralização no SUS no período anterior (1998-2002) que, devido à intensa normatização atrelada aos incentivos financeiros, teriam gerado, entre outros fatores, a burocratização das relações intergovernamentais e uma fragmentação acentuada dos mecanismos de transferência de recursos federais.

Assim, durante a primeira gestão ministerial da saúde no governo Lula (2003 a meados de 2005), a discussão sobre a descentralização teve como foco a necessidade de substituição dos processos e instrumentos adotados para a habilitação dos estados e municipios por novas práticas, queinduzissem a ação coordenada e cooperativa entre os três gestores do SUS. Dentre os desafios mais relevantes, destacavam-se: a necessidade de adoção decritérios derepartição maisjusta entre as unidades federadas e de formulação de modalidades inovadoras para as transferências dos recursos financeiros; a formulação de metas e objetivos sanitários para a regulação e avaliação das ações de saúde oferecidas pelo SUS; a formulação de estratégias para a organização da gestão regional do sistema; e a definição de uma proposta de organização das redes de atenção, tendo a atenção primária como ordenadora.

Após amplas discussões, o documento contendo as diretrizes do Pacto pela Saúde 2006Consolidação do SUS foi aprovado na Comissão Intergestores Tripartite e no Consel ho Nacional de Saúde e consolidado por meio de duas portarias ministeriais, incluindo três dimensões: pela Vida, em Defesa do SUS e de Gestão ${ }^{18,19}$.

Apresentado como uma inovação capaz de fortalecer a gestão descentralizada do sistema, 0 Pacto propõe a redefinição das responsabilidades coletivas dos três entes gestores e a pactuação de prioridades, objetivos e metas a serem atingi- dos no âmbito setorial. Posteriormente, vários documentos são publicados com o objetivo de detal har algumas propostas e instrumentos operacionais do Pacto pela Saúde, bem como defornecer orientações para a negociação intergovernamental e a implantação de estratégias e políticas em áreas específicas. As proposições do M inistério da Saúde assumem a feição de compromissos pactuados reunidos em quatorze Cadernos da série Pactos pela Saúde publicados até dezembro de 2010.

0 Pacto pela Vida corresponde à definição de prioridades, que se traduzem em objetivos e metas de mel horia das condições de saúde da população, a serem acordadas pelas três esferas de governo. Já o Pacto em Defesa do SUS, indica a necessidade de um movimento político mais amplo, explicitando al gumas iniciativas e ações para a garantia dos princípios e diretrizes da reforma sanitária, que transcendam os limites setoriais e aumentem a base de apoio à política de saúdenos governos e na sociedade. Por sua vez, o Pacto de Gestão, estabelecediretrizes para o aprimoramento da gestão do SUS em oito aspectos: descentralização, regionalização, financiamento, planejamento, Programação Pactuada el ntegrada (PPI), regulação, participação e controle social, gestão do trabalho e educação na saúde.

O Pacto pela Saúde diferencia-se dos instrumentos anteriormente adotados no âmbito do SUS por propor a formalização de acordos intergovernamentais em diversos âmbitos da gestão e atenção à saúde. A adesão ao Pacto é feita por meio do preenchimento e assinatura de Termos de Compromisso de Gestão (TCG) pelos gestores, que devem ser aprovados e homologados nas respectivas Comissões Intergestores em âmbito estadual e nacional, substituindo os antigos processos de habilitação às Normas 0 peracionais do SUS.

Os Termos compreendem atribuições e responsabilidades sanitárias, objetivos e metas de melhoria associados a um conjunto de indicadores voltados para o monitoramento e avaliação do Pacto de Gestão e pela Vida. Há um modelo especifico para cada ente federativo - município, estado, Distrito Federal eUnião - justificado pelas diferentes responsabilidades previstas para cada um deles, estando organizados em sete eixos prioritários: i) responsabilidades gerais de gestão do SUS; ii) responsabilidades sobre a regionalização; iii) responsabilidades sobre o planejamento e a programação; iv) responsabilidades da regulação, controle, avaliação e auditoria; v) responsabilidades sobre a participação e con- 
trolesocial; vi) responsabilidades sobrea gestão do trabalho; e, vii) responsabilidades na educação em saúde.

0 mecanismo de adesão ao Pacto reconfigura as relações do Ministério da Saúde com os estados e municípios, até então instituídas por meio de requisitos formais associados a incentivos financeiros. Sob o aspecto da transferência de responsabilidades e recursos federais, não altera de imediato o volume de recursos repassados pela União para o custeio do SUS, nem amplia a autonomia no gasto descentralizado destes recursos.

De fato, as mudanças no que se refere aos mecanismos definanciamento envolvem a unificação das centenas de repasses real izados anteriormente, por meio da criação de cinco grandes blocos para transferência de recursos federais vinculados ao SUS: (1) atenção Básica; (2) atenção de média eal ta complexidade ambulatorial e hospitalar; (3) vigilância em saúde; (4) assistência farmacêutica; (5) gestão do SUS. Posteriormente, foi criado um sexto bloco referente aos investimentos.

Em que pese a redução do parcelamento eda fragmentação das transferências, é preciso considerar que os dispositivos que regem a distribuição de grande parte dos recursos permanecem inalterados. Cada bloco é constituído por componentes que agregam antigos e novos incentivos financeiros federais, eque, por sua vez, seguem critérios e condicionantes para transferência e usos definidos em portarias específicas. Assim, mesmo que tenha havido o propósito de alterar a capacidade de gestão orçamentária dos governos municipais e estaduai $s^{20}$, os repasses permaneceram sendo efetivados mediante sua certificação ao referido programa ea implementação das ações a que se destinam, mantendo o caráter indutório das transferências federais do SUS e o poder regulatório do M inistério no contexto do Pacto pela Saúde.

No queconcerneà regi onalização, destaca-se o resgate de seu conteúdo político, ao admitir que a organização do sistema de saúde deva levar em conta a diversidade dos elementos que caracterizam e distinguem o território brasileiro e buscar a complementaridade entre as regiões ${ }^{21}$, enfatizando a importância da condução e da adaptação estadual e restringindo as determinações federais nesse processo. Propõe-se, ainda, a implantação de instâncias colegiadas de gestão permanente dos espaços regionais definidos nos Planos Diretores de Regionalização: os Colegiados de Gestão Regional (CGR).
Formados por representação do estado (do nível central ou das estruturas de representação regional das Secretarias deEstado de Saúde) edo conjunto de municípios em regiões específicas ${ }^{22}$, esses Colegiados constituem canais de negociação e decisão intergovernamental, com regras próprias efuncionamento estável, que visam fortalecer a governança regional do SU S9. Enquanto instâncias privilegiadas para identificação de problemas, definição de prioridades e soluções para organização da rede assistencial, podem favorecer a constituição de objetivos compartilhadose o estabel ecimento de uma lógica voltada para as necessidades regionais de saúde na provisão dos serviços (visão regional).

Em síntese, o Pacto pela Saúderepresenta uma inflexão nas relações federativas por enfatizar a necessidade dearticulação de ações e cooperação intergovernamental em vários âmbitos da política de saúde e tentar ampliar as funções dos entes subnacionais na condução do processo de descentralização e regionalização no SUS. M antidos o poder regulatório e de indução de políticas nacionais por meio das transferências federais, os distintos ritmos e graus de implantação do Pacto pela Saúde refletem, em última instância, o modo decondução da política de saúdeem âmbito estadual, bem como a diversidade de amadurecimento das relações federativas em cada um dos estados brasileiros.

\section{M etodologia}

O estudo se apoiou no referencial de análise de políticas públicas que tem como objeto o conteúdo e o curso da ação proposta por um ator ou grupo de atores, seus determinantes, suas finalidades, seus processos e suas consequên cias ${ }^{23,24}$.

A análise também incorporou as contribuições do institucionalismo histórico ${ }^{25,26}$, tendo em vista o propósito de identificação e sistematização dos fatores condicionantes do processo de implantação do Pacto pela Saúde. Valorizou-se nesse sentido a noção de dependência de trajetória ( path-dependence), relacionada à idéia de que acontecimentos do passado podem dar vazão a uma cadeia de determinações que influenciam as decisões políticas no presente ${ }^{27}$.

Foram considerados dois ei xos de análise interligados: a caracterização da dinâmica de implantação do Pacto no conjunto do país; a identificação dos condicionantes da adesão ao Pacto nos estados brasileiros, considerando os contextos políticos, econômicos e sociais específicos. 
Para realização da pesquisa empírica adotaram-se fontes primárias e secundárias, bem como métodos quantitativos e qualitativos para processamento das informações.

Um amplo conjunto de dados foi obtido junto à Secretaria Executiva da Comissão Intergestores Tripartite e do Departamento de Apoio a Gestão Descentralizada do Ministério da Saúde. As informações foram consolidadas para o período de 2006 a setembro de 2010 (última informação disponível) e agregadas de modo a permitir a compreensão da dinâmica (ritmos e graus) de implantação do Pacto nas distintas regiões e estados brasileiros.

Foram analisados, ainda, documentos produzidos nesse período, entre outros, atas das reuniões da Comissão Intergestores Tripartite e das Comissões I ntergestores Bipartites estaduais, re latórios, planos e normativas do Ministério da Saúde e das Secretarias de Estado de Saúde, bem como as portarias que regulamentam as diretrizes do Pacto pela Saúde. Também foram realizadas 70 entrevistas semiestruturadas com dirigentes federais, estaduais e membros dos consel hos deSecretários M unicipais deSaúde. 0 cotejamento dessas diferentes fontes (documentos e entrevistas) àluz do referencial teórico numa perspectiva crítico-reflexiva ${ }^{28,29}$, permitiram a identificação de condicionantes que conformam contextos específicos e influenciam a implantação do Pacto pela saúde em âmbito estadual.

A pesquisa foi aprovada pelos Comitês de Ética das organizações acadêmicas envolvidas. Todos os entrevistados assinaram um Termo de Consentimento LivreeEsclarecido, cujo conteúdo assegurava-Ihes o direito de recusa de participação e de sigilo das informações fornecidas.

\section{Resultados}

Dinâmica de implantação

do Pacto pela Saúde nos estados brasileiros

A adesão dos governos estaduais ao Pacto ocorreu de modo gradual no período compreendido entre 2006 e2010. Assim, em 2006, apenas o Tocantins formalizou sua adesão; em 2007, quatorze estados e, em 2008, nove estados. Os estados do Piauí e Amazonas foram os últimos a aderir ao Pacto etiveram seus processos aprovados pela Comissão Intergestores Tripartite em 2009 e 2010, respectivamente. Desse modo, em quatro anos, todos os estados formalizaram acordosintergovernamentais no âmbito do SUS.
A exemplo do que ocorreu com os estados, os acordos formalizados pelos municipios também apresentaram ritmos diversos. No periodo compreendido entre 2006 a setembro de 2010, foram homologados na Comissão Intergestores Tripartite 3.789 adesões ao Pacto, que representam $68,1 \%$ do total de municipios existentes no país. A maioria das homologações se concentrou no ano de 2008 (66,2\%); em 2009, ano em que varias administrações municipais passaram por mudanças de governo em função dos resultados eleitorais, houve decréscimo nas adesões municipais ( 8,5\%), seguido de uma retomada em 2010 (18,5\%). Contudo, dados os milhares de municipios existentes no país, o ritmo de adesão municipal ao Pacto não pode ser comparado ao dos estados no mesmo período.

Esses acordos têm obedecido às dinâmicas loco-regionais e ocorrido de modo mais ou menos articulado e complementar às adesões estaduais. Embora haja uma elevada dispersão geográfica dos municípios que aderiram ao Pacto, a observação da Figura 1 permite constatar que nas regiões do centro-sul do país este processo ocorreu de forma mais intensa, concentrando o maior numero deestados com percentual deadesão municipal superior a $70 \%$.

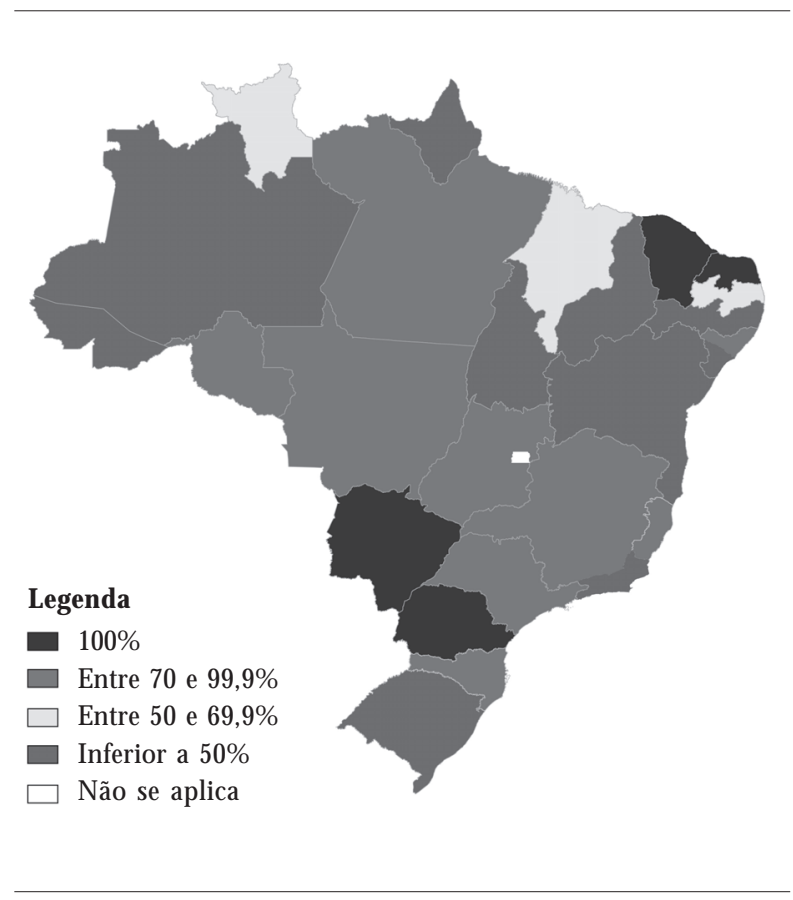

Figura 1. Proporção de adesões municipais ao Pacto pela Saúde nos estados Brasil, 2010.

Fonte: Brasi ${ }^{30}$

N ota: Os dados se referem ao mês de setembro de 2010. 
Os dados possibilitam a agregação dos estados brasileiros em quatro grupos, segundo a situação de adesão municipal ao Pacto em setembro de 2010:

Grupo 1: Estados com baixo percentual de adesão muncipal (abaixo de 50\%): Acre, Amazonas, Amapá, Bahia, Pernambuco, Piauí, Rio de Janeiro, Rio Grande do Sul, Sergipe e Tocantins.

Grupo 2: Estados com percentuais médios de adesão municipal (entre 50\% e 70\%): M aranhão, Paraíba e Roraima.

Grupo 3: Estados com alto percentual adesão municipal (acima de 70\% até 99\%): Alagoas, Espírito Santo, Goiás, M inas Gerais, M ato Grosso, Pará, Rondônia, Santa Catarina e São Paulo.

Grupo 4: Estados com adesão total dos municípios (100\%): Ceará, M ato Grosso do Sul, Paraná e Rio Grande do Norte.

Destaque-se que o estado do M ato Grosso do Sul, na região Centro-O este, foi o único a as- sociar, no momento da sua adesão em 2007, 100\% dos municipios.

A Tabela 1 informa sobrea dinamicidade dos processos de adesão municipal em cada estado, evidenciando uma tendência geral à elevação entre os anos de 2007 a 2010. Assim, se em 2007, 24 estados apresentavam um percentual de adesão municipal inferior a 50\%, em 2008 houvedecréscimo para 17 estados nesta condição, em 2009, para 15 estados, e, em setembro de 2010, para 10 estados. Cabe ainda destacar que, no período de 2006 a 2010, dos 26 estados, 19 alteraram positivamente a situação do percentual de adesão municipal, sendo que quatro estados apresentam atualmente $100 \%$ de adesão municipal.

Já o Q uadro 1 oferece al guns el ementos para a análise das relações existentes entre as adesões estaduais precoces (2006 a 2008) e tardias (após 2009) com o percentual de adesão municipal registrados nos estados até setembro de 2010, clas-

\begin{tabular}{|c|c|c|c|c|c|c|c|}
\hline Estado & $\begin{array}{l}\text { Ano de } \\
\text { adesão } \\
\text { estadual }\end{array}$ & $\begin{array}{c}\text { No de } \\
\text { municípios } \\
\text { existentes }\end{array}$ & $\begin{array}{l}\text { Percentual } \\
\text { Adesão } \\
\text { Municipal } \\
2006\end{array}$ & $\begin{array}{l}\text { Percentual } \\
\text { Adesão } \\
\text { M unicipal } \\
2007\end{array}$ & $\begin{array}{l}\text { Percentual } \\
\text { Adesão } \\
\text { Municipal } \\
2008\end{array}$ & $\begin{array}{l}\text { Percentual } \\
\text { Adesão } \\
\text { M unicipal } \\
2009\end{array}$ & $\begin{array}{l}\text { Percentual } \\
\text { Adesão } \\
\text { M unicipal } \\
2010\end{array}$ \\
\hline$A C$ & 2008 & 22 & Nenhuma & Inferior a $50 \%$ & Inferior a $50 \%$ & Inferior a $50 \%$ & Inferior a $50 \%$ \\
\hline$A L$ & 2007 & 102 & Nenhuma & Inferior a 50\% & Inferior a $50 \%$ & Entre $50 \%$ e $70 \%$ & Acima de $70 \%$ \\
\hline$A M$ & 2010 & 62 & Nenhuma & Nenhuma & Inferior a $50 \%$ & Inferior a $50 \%$ & Inferior a $50 \%$ \\
\hline$A P$ & 2007 & 16 & Nenhuma & Nenhuma & N enhuma & Nenhuma & Inferior a $50 \%$ \\
\hline $\mathrm{BA}$ & 2007 & 417 & Nenhuma & Inferior a $50 \%$ & Inferior a $50 \%$ & Inferior a $50 \%$ & Inferior a $50 \%$ \\
\hline CE & 2007 & 184 & Nenhuma & Acima de $70 \%$ & Acima de $70 \%$ & Acima de $70 \%$ & $100 \%$ \\
\hline ES & 2008 & 78 & Nenhuma & Nenhuma & Entre $50 \%$ e $70 \%$ & Acima de $70 \%$ & Acima de $70 \%$ \\
\hline GO & 2007 & 246 & Nenhuma & Inferior a 50\% & Inferior a 50\% & Inferior a $50 \%$ & Acima de $70 \%$ \\
\hline $\mathrm{MA}$ & 2007 & 217 & Nenhuma & Inferior a $50 \%$ & Inferior a $50 \%$ & Inferior a $50 \%$ & Entre $50 \%$ e $70 \%$ \\
\hline MG & 2008 & 853 & Nenhuma & Inferior a $50 \%$ & Acima de $70 \%$ & Acima de $70 \%$ & Acima de $70 \%$ \\
\hline M S & 2007 & 78 & Nenhuma & $100 \%$ & $100 \%$ & $100 \%$ & $100 \%$ \\
\hline M T & 2007 & 141 & Nenhuma & Inferior a $50 \%$ & Entre $50 \%$ e $70 \%$ & Entre $50 \%$ e $70 \%$ & Acima de $70 \%$ \\
\hline PA & 2008 & 143 & Nenhuma & Nenhuma & Nenhuma & Nenhuma & Acima de $70 \%$ \\
\hline PB & 2008 & 223 & Nenhuma & Inferior a 50\% & Inferior a $50 \%$ & Inferior a $50 \%$ & Entre $50 \%$ e $70 \%$ \\
\hline$P E$ & 2008 & 184 & Nenhuma & Inferior a 50\% & Inferior a $50 \%$ & Inferior a $50 \%$ & Inferior a $50 \%$ \\
\hline PI & 2009 & 224 & Nenhuma & Nenhuma & N enhuma & Inferior a $50 \%$ & Inferior a $50 \%$ \\
\hline PR & 2007 & 399 & Nenhuma & Inferior a $50 \%$ & Acima de $70 \%$ & Acima de $70 \%$ & $100 \%$ \\
\hline RJ & 2007 & 92 & Nenhuma & Nenhuma & Inferior a $50 \%$ & Inferior a $50 \%$ & Inferior a $50 \%$ \\
\hline RN & 2007 & 167 & Nenhuma & Nenhuma & Acima de $70 \%$ & Acima de $70 \%$ & $100 \%$ \\
\hline RO & 2008 & 52 & Nenhuma & Nenhuma & Entre $50 \%$ e $70 \%$ & Acima de $70 \%$ & Acima de $70 \%$ \\
\hline $\mathrm{RR}$ & 2007 & 15 & Nenhuma & Inferior a $50 \%$ & Inferior a 50\% & Entre $50 \%$ e $70 \%$ & Entre $50 \%$ e $70 \%$ \\
\hline RS & 2007 & 496 & Nenhuma & Nenhuma & Nenhuma & Nenhuma & Inferior a $50 \%$ \\
\hline SC & 2008 & 293 & Nenhuma & Inferior a $50 \%$ & Inferior a $50 \%$ & Inferior a $50 \%$ & Acima de $70 \%$ \\
\hline SE & 2008 & 75 & Nenhuma & Nenhuma & Nenhuma & Nenhuma & Nenhuma \\
\hline SP & 2007 & 645 & Nenhuma & Inferior a $50 \%$ & Acima de $70 \%$ & Acima de $70 \%$ & Acima de $70 \%$ \\
\hline TO & 2006 & 139 & Nenhuma & Inferior a $50 \%$ & Inferior a $50 \%$ & Inferior a $50 \%$ & Inferior a $50 \%$ \\
\hline
\end{tabular}

Fonte: Brasil ${ }^{30}$.

N ota: Os dados de 2010 se referem ao mês de setembro. 
sificando-os em baixo, médio ou alto. O bservasequenão há casos quecombinem percentual de adesão municipal alto ou médio com processos de adesão estadual tardia, fato que sugere a rele vância do papel indutor e coordenador do gestor estadual na implantação do Pacto.

Por outro lado, há estados que adotaram um ritmo aparentemente mais lento nos processos de adesão estadual e municipal. Alguns desses estados optaram por atualizar os recortes regionais vigentes em seus Planos Diretores de Regionalização, bem como por aprofundar as negociações intergovernamentais no âmbito dos Colegiados de Gestão Regional, de modo a favorecer a adesão conjunta dos municípios ao Pacto em regiões específicas, indicando uma preocupação em qualificar o processo de descentralização da gestão. São conduções que revelam as expectativas dos gestores em relação ao fortalecimento dos processos de regionalização, num contexto de implantação ou reconfiguração de instâncias de pactuação regional.

Os Colegiados de Gestão Regional vêm sendo instituídos gradativamente no Brasil como instâncias de planejamento, pactuação e gestão intergovernamental da saúde nos espaços regionais, assumindo caráter complementar às Comissões Intergestores já existentes no SUS.

A exemplo do que se verifica em relação aos processos de adesão estadual e municipal ao Pacto, a implantação dos Colegiados teve seu inicio no ano de 2006 e tem obedecido a ritmos diverSOS, cuja determinação se relaciona às condições especificas da gestão e da organização do SU S em cada estado. Entre 2006 e setembro de 2010, foram implantados 417 Colegiados de Gestão $R e-$ gional no país, que abrangem 5.332 municípios em 24 estados, dado que Roraima e M aranhão não instituíram Colegiados (Figura 2).
Embora obedecendo a dinâmicas diversas, contata-se que, em 2007, houve maior associação entre os processos de adesão estadual ao Pacto, expansão das adesões municipais e implantação dos Colegiados.

Os Colegiados mantêm correlação com processos de regionalização previamente existentes, sendo influenciados pela prática de revisão eatualização do desenho regional adotado no âmbito estadual. Em alguns estados, essa atualização

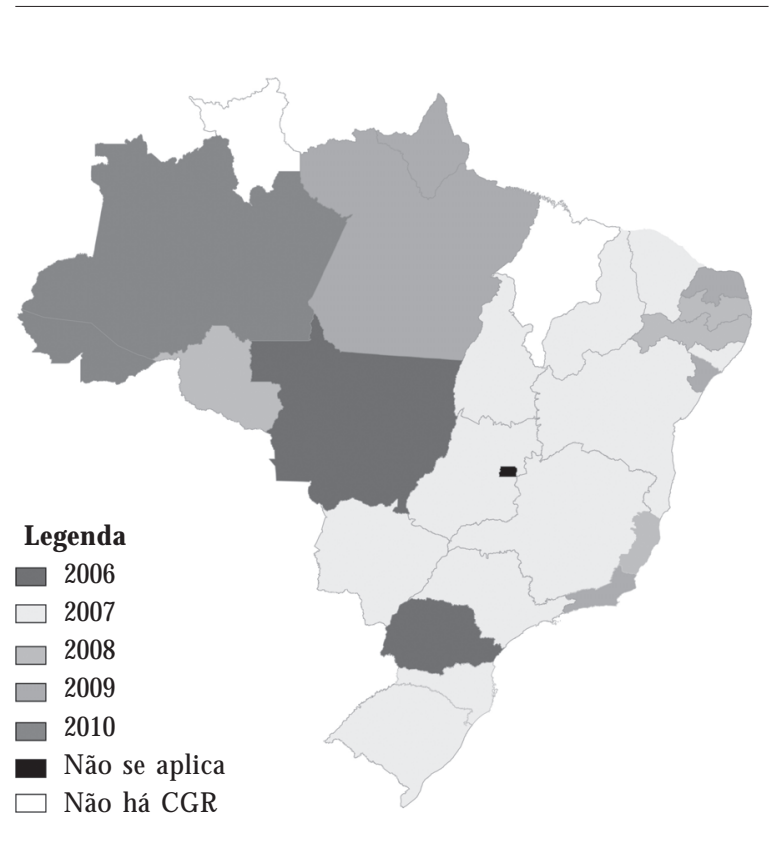

Figura 2. Ano de Implantação dos Colegiados de Gestão Regional nos estados. Brasil, 2006 a 2010.

Fonte: Brasi|31.

N ota: Os dados de 2010 se referem ao mês de setembro.

Quadro 1. Síntese da situação de adesão estadual e municipal ao Pacto pela Saúde nos estados - Brasil, 2006 a 2010.

\begin{tabular}{|l|c|c|c|}
\hline \multicolumn{1}{|c|}{$\begin{array}{c}\text { Adesão estadual } \\
\text { e municipal } \\
\text { ao Pacto pela Saúde }\end{array}$} & $\begin{array}{c}\text { Alto Percentual de } \\
\text { adesão municipal } \\
\text { (superior a 70\% em 2010) }\end{array}$ & $\begin{array}{c}\text { Médio Percentual } \\
\text { de adesão municipal } \\
\text { (entre 50\% e 70\% em 2010) }\end{array}$ & $\begin{array}{c}\text { Baixo Percentual } \\
\text { de adesão municipal } \\
\text { (inferior a 50\% em 2010) }\end{array}$ \\
\hline $\begin{array}{l}\text { Adesão Estadual } \\
\text { Precoce } \\
\text { ( 2006- 2008) }\end{array}$ & $\begin{array}{c}\text { AL, CE, ES, GO, M G, M S, } \\
\text { M T, PA, PR, RN, RO, SC, SP }\end{array}$ & M A, PB, RR & $\begin{array}{l}\text { AC, AP, BA, PE, RJ, RS, } \\
\text { SE, TO }\end{array}$ \\
\hline $\begin{array}{l}\text { Adesão Estadual } \\
\text { Tardia (após 2009) }\end{array}$ & -- & -- & AM, PI \\
\hline
\end{tabular}

Fonte: Brasi ${ }^{30}$.

Nota: Os dados de 2010 se referem ao mês desetembro. 
considerou os conteúdos das propostas contempladas no Plano Estadual de Saúde, o que indica um esforço de alinhamento prévio entre instrumentos de planejamento que orientam as decisões gestoras no contexto do SUS.

Por outro lado, há situações nas quais os estados definiram seus Colegiados de Gestão Regional após 2007, sem que tenha havido uma precedenterevisão dos planos de regionalização. Em muitos casos, os processos de constituição dos Colegiados e 0 debate nestas instâncias não foram suficientes para nortear a adesão articulada entre os governos ao Pacto. Por vezes as dificuldades evidenciadas por estas instâncias para se constituirem como fóruns permanentes de negociação intergovernamental devem-seà falta de sua correspondência com regiões reconhecidas e acordadas pelo conjunto degestores do SU S nestes estados. Tal situação dificulta a consolidação de uma cultura de debate enegociação e fragiliza a governança regional na saúde.

\section{Condicionantes estaduais \\ da implantação do Pacto pela Saúde}

As informações referentes à implantação do Pacto pela Saúde nos estados sugere a multiplicidade das experiências de descentralização e regionalização em curso no país. Isso porque, dado o importante papel adquirido pelas instâncias subnacionais (estados e municípios) na condu- ção desses processos, vários são os modelos adotados para lidar com a diversidade de contextos elugares existentes.

Além disso, diversos são os fatores e a natureza dos fenômenos que condicionam e particularizam as experiências estaduais, influenciando os ritmos e os graus de adesão ao Pacto pela Saúde ea implantação dos Colegiados de Gestão Regional. A pesquisa permitiu a identificação ea agregação destes fatores em três dimensões sistematizadas no Quadro 2.

A análise conjunta destes fatores nas três dimensões propostas configura os contextos de implantação do Pacto nos estados. Assim, fatores de natureza histórico-estrutural, ligados à história de conformação dos estados, às dinâmicas socioeconômicas e às características dos sistemas de saúde (complexidade, perfil e distribuição da oferta de serviços) foram determinantes para os avanços e as dificuldades enfrentados no processo de descentralização e de regionalização. Também se identificaram aspectos de ordem político-institucional, entre os quais se destacaram: o legado de implantação de políticas prévias que enfatizam a descentralização e a regionalização; 0 aprendizado institucional acumulado pelas instâncias colegiadas do SUS (entre el as a Comissão Intergestores Bipartites e os Consel hos de Representação dos Secretários M unicipais de Saúde) e pel os governos estaduais e municipais nos diversos campos e funções gestoras

Quadro 2. Fatores condicionantes da implantação do Pacto pela Saúde nos estados - Brasil, 2006 a 2010.

\begin{tabular}{|l|l|}
\hline Dimensões & \multicolumn{1}{c|}{ Condicionantes } \\
\hline Histórico-estrutural & $\begin{array}{l}\text { - Histórico de conformação do estado e de suas regiões (antiguidade do processo, } \\
\text { presença de identidade regional) } \\
\text { - Dinâmica socioeconômica } \\
\text { - Características do sistema de saúde (complexidade, perfil e distribuição da oferta } \\
\text { de serviços) }\end{array}$ \\
\hline Político-institucional & $\begin{array}{l}\text { - Legado de implantação de políticas prévias de descentralização e regionalização } \\
\text { da saúde } \\
\text { - Aprendizado institucional acumulado pelas instâncias colegiadas do SUS e pelos } \\
\text { governos estaduais e municipais nos diversos campos e funções gestoras da saúde- } \\
\text { Existência de uma cultura de negociação intergovernamental } \\
\text { - Qualificação técnica e política da burocracia governamental } \\
\text { - M odos mais ou mesmo democráticos de operação e condução das políticas de saúde }\end{array}$ \\
\hline Conjuntural & $\begin{array}{l}\text { - Perfil e trajetória dos atores políticos } \\
\text { - Dinâmica das relações intergovernamentais } \\
\text { - Prioridade do Pacto na agenda governamental dos estados e municípios }\end{array}$ \\
\hline
\end{tabular}


da saúde (principalmenteno quese refereàsfunções de planejamento e regulação); a existência deuma cultura de negociação intergovernamental; a qualificação técnica epolítica da burocracia governamental, e; os modos mais ou menos democráticos de operação e condução das políticas de saúde nos estados. Da mesma forma, fatores conjunturais, particularmenteaqueles relacionados à ação política, como o perfil e a trajetória dos atores políticos, a dinâmica das relações intergovernamentais e a prioridade do Pacto na agenda governamental, repercutiram no processo decisório e nas escolhas realizadas.

Alguns estados brasileiros, por exemplo, foram conformados ainda no período colonial e apresentam processos muito antigos de descentralização e regionalização na saúde, iniciados na primeira metade do século passado, incluindo a conformação de estruturas de representação regional das Secretarias de Saúde (tais como M inas Gerais, Rio Grande do Sul, São Paulo, Bahia e Pernambuco). Outros foram formados mais recentemente, sendo sua identidade estadual ou regional ainda muito incipiente. $N$ este caso, ressaltam-se: o Rio de Janeiro, que se constituiu em 1975 por meio da fusão entre o estado da Guanabara (antigo Distrito Federal) e o estado do Rio de aneiro; o Tocantins; e os antigos territórios brasileiros transformados em estados (Amapá, Roraima e Rondônia).

Além disso, também atuaram como elementos decisivos na implantação do Pacto pela Saúde, a experiência acumulada no planejamento governamental, as formas de organização e a cultura de negociação intergovernamental adquiridas pelas secretarias estaduais e municipais de saúde e instâncias colegiadas no estado, a experiência com estratégias de formalização de parcerias (por exemplo, consórcios de saúde e contratos de gestão). N essa situação, encontram-se os estados do Ceará, M ato Grosso, M ato Grosso do Sul, M inas Gerais, Paraná e São Paulo. Cabe destacar que, em alguns estados, a implantação do Pacto foi potencializada pela articulação de políticas governamentais que, ao contemplarem a descentralização de estruturas e processos como linha estruturante da ação do governo estadual, ampliaram o alcance das proposições do setor saúde.

Algumas dificuldades de constituição de espaços de representação regional nos estados de correm do fato de que, muitas vezes, a integração dos serviços de saúde obedece a lógicas territoriais que extrapolam suas fronteiras (municí- pios cujos territórios se relacionam com outros estados). Há também situações de ingerência do poder político eleitoral (os chamado bolsões eleitorais de determinados políticos) em certas regiões e pesadas heranças centralizadoras em alguns estados da federação ( como refletem as experiências dos estados do N ordeste).

Outras razões que tensionam a consolidação desses espaços vinculam-se à concentração de recursos e tecnologias em al gumas regiões (principalmente, áreas metropolitanas ou sede de capitais em sua maioria situadas no litoral), às dinâmicas próprias de alguns territórios (caso dos estados da região Norte) eàs desigual dades socioeconômicas das regiões.

Além disso, a atuação de interlocutores com forterepresentatividade político-institucional, na negociação e na mediação de conflitos, se constituiu como fator distintivo entre os estados nos processos de implantação do Pacto pela Saúde. Essa atuação foi identificada tanto entre os gestores municipais, quando agem de forma organizada e participativa, quanto no âmbito das secretarias estaduais de saúde, pela sua capacidade de diálogo, coordenação e condução dos processos.

A presença de atores públicos com legitimidade e poder político necessários para a superação de conflitos - comuns em momentos de renovação de práticas gestoras - quando associados, no âmbito institucional, à existência de equipes técnicas qualificadas, foi decisiva em alguns casos para a adoção de novas experiências de planejamento e gestão em saúde (como sugere a experiência deSergipe).

Por outro lado, identificaram-sesituações nas quais a adesão estadual bem como os processos que a ela se relacionam, como as adesões municipais e a implantação dos Colegiados de Gestão Regional, foram conduzidas de modo burocrático e cartorial, sem que ten ha havido a necessária disposição para o debate por parte dos gestores, resultando em baixa ou nenhuma repercussão nas praticas institucionais vigentes.

Em síntese, a implementação do Pacto pela Saúde se associou, em cada estado, aos processos de descentralização e regionalização anteriores, ao desenvolvimento das capacidades de negociação loco-regionais e ao grau de articulação existente entre os representantes do Consel ho de Representação das Secretarias M unicipais deSaúde e da Secretaria Estadual de Saúde, no sentido de gerar consensos sobre a divisão de responsabilidades gestoras e os desenhos regionais adotados em cada estado. 


\section{Conclusões}

Nas duas últimas décadas, observam-se sucessivos aprimoramentos das relações intergovernamentais na implementação do SUS. O Pacto pela Saúde representa um movimento deinflexão nos mecanismos de coordenação federativa na política de saúde brasileira, com valorização das esferas estaduais e municipais e a criação de novas instâncias regionais.

No entanto, a pesquisa realizada sugere a permanência de alguns desafios, sendo as estratégias e instrumentos propostos no âmbito do Pacto insuficientes per se para prover os avanços necessários à condução da descentralização e da regionalização da saúde nos estados brasileiros.

Em primeiro lugar, não estão claras as relações entre os processos de regionalização e a assinatura dos Termos de Compromisso de Gestão, que formalizam os acordos intergovernamentais no Pacto. As informações consolidadas neste estudo permitem constatar que, nas bases atuais, a adesão dos governos subnacionais ao Pacto pode ocorrer sem quea regionalização seja defato fortalecida esem queesta representequalquer avanço para a descentralização do sistema em âmbito estadual.

Os Colegiados de Gestão Regional, em processo de implantação, apresentam funcionamento irregular e incipiente em muitas regiões e, em geral, não possuem estrutura e recursos suficientesque permitam o desenvolvimento de parcerias ea resolução de conflitos federativos. Além disso, há a necessidade de assegurar a implantação de novos fluxos e de modal idades de relacionamento entre tais colegiados e as comissões intergestores nos estados, no sentido de superar dificuldades quepossam existir no exercício descentralizado do poder de negociação e de decisão.

Em segundo lugar, tal como já sugerido em outros estudo ${ }^{32}$, permanece o risco de desarticulação entre os processos de planejamento e de pactuação intergovernamental em curso nos estados, devido à pouca val orização dos instrumentos e recursos relativos ao planejamento regional no bojo da proposta. Tentativas recentes de articulação entreas estratégias de pactuação intergovernamental e a elaboração dos instrumentos de planejamento setoriais (os Planos deSaúde, a Programação Anual de Saúde e o Relatório Anual de Gestão) visam minorar este problema ${ }^{33}$.

Em terceiro lugar, cabe mencionar a fragilidadedo modelo deintervenção federal embutido na proposta do Pacto. A relação entre a celebração dos pactos e o papel federal nesse processo poderia ser aprimorada, com maior valorização do planejamento nacional, quenão se restringe à coordenação de um processo "de base local e ascendente", visto que existem atributos próprios do planejamento em cada âmbito territorial.

As experiências revelam que falta avançar na configuração de estratégias e instrumentos de planejamento, regulação e financiamento que possam apoiar a conformação de sistemas públicos de saúde regionais em diferentes recortes territoriais (nos espaços definidos pelos Colegiados de Gestão Regional, nas regiões de frontei$\mathrm{ra}$, áreas metropolitanas, reservas indígenas e áreas de proteção ambiental, entre outras). Também é preciso desenvolver mecanismos que favoreçam a participação de uma ampla gama de atores e o estabelecimento de relações coordenadas e cooperativas entre governos, organizações e cidadãos nos espaços regionais.

Por outro lado, problemas de ordem estrutural como as desigualdades territoriais dificilmente podem ser resolvidos somente pela ação articulada dos estados e municípios, sem uma efetiva atuação do governo federal. As múltiplas realidades regionais exigem o fortalecimento da lógica territorial no processo de planejamento e formulação de políticas de saúde, bem como um esforço financeiro adicional da União e dos estados, de modo a permitir uma diversificação de políticas e investimentos que relacionem as necessidades de saúde às dinâmicas territoriais específicas. As políticas setoriais, particularmentea descentralização e a regionalização, só poderão ter viabilidade se articuladas a políticas dedesenvolvimento regional de médio e longo prazo. 


\section{Colaboradores}

LD Lima, LFN Queiroz, CV M achado eALD Viana foram responsáveis pela concepção, desenvolvimento, análise das informações, redação e revisão do artigo.

\section{Agradecimentos}

A pesquisa contou com recursos do Ministério da Saúde, em parceria com a O rganização Panamericana de Saúde; do Conselho Nacional de Desenvolvimento Científico e Tecnológico (CN Pq); da Fundação Carlos Chagas de Amparo à Pesquisa do Estado do Rio de Janeiro (FAPERJ) e do PAPES/Fundação Oswaldo Cruz. Agradecemos às equipes do Departamento de A poio a Gestão Descentralizada do M inistério da Saúde e da Secretaria Técnica da Comissão Intergestores Tripartite pelo fornecimento de informações.

\section{Referências}

1. Brasil. Constituição da República Federativa do Brasil: promulgada em 5 de outubro de 1988. Brasília: Senado Federal; 1988.

2. Brasil. Lei no. 8.080 , de 19 de setembro de 1990 . Diário Oficial da União 1990; 20 set.

3. Melo AC. Crise federativa, guerra fiscal e "hobbesianismo municipal": efeitos perversos da descentralização? São Paulo Perspec 1996; 10(3):11-20.

4. Ribeiro PT. A descentralização da ação governamental no Brasil dos anos noventa: desafios do ambiente político-institucional. Cien Saude Colet 2009; 13(3):819-828.

5. Affonso R, Silva PLB, organizadores. A federação em perspectiva: ensaios seleccionados. São Paulo: Edições Fundap; 1995.

6. Mendes EV. Uma Agenda para a Saúde. São Paulo: Editora Hucitec; 1999.

7. Campos GWS. Efeitos paradoxais da descentralização do Sistema Único de Saúde do Brasil. In: Fleury $\mathrm{S}$, organizadora. Democracia, descentralização e desenvolvimento: Brasil e Espanha. Rio de Janeiro: FGV; 2006. p. 417-442.

8. Viana ALD, Ibañez N, Elias PEM, Lima LD, Albuquerque $\mathrm{M}$, Iozzi FL. Novas perspectivas para a regionalização da saúde. São Paulo Perspec 2008; 22(1): 92-106.

9. Viana ALD, Lima LD, Ferreira M P. Condicionantes estruturais da regionalização na saúde: tipologia dos Colegiados de Gestão Regional. Cien Saude Colet 2010; 15(5):2317-2326.

10. Lijphart A. Modelos de democracia: desempenho e padrões de governo em 36 países. Rio de Janeiro: Civilização Brasileira; 2003.

11. Pierson P, Leibfried $S$. The dynamics of social policy integration. In: Leibfried S, Pierson P, editors. European social policy: between fragmentation and integration. Washington: The Brookings Institution; 1995.

12. Arretche M. Federalismo e relações intergovernamentais no Brasil: a reforma de programas sociais. Dados 2002; 45(3):431-458.

13. Abrucio FL. A coordenação federativa no Brasil: a experiência do período FHC e os desafios do governo Lula. Rev Sociol Polit 2005; 24:41-67.

14. Viana ALD, M achado CV. Descentralização e coordenação federativa: a experiência brasileira na saúde. Cien Saude Colet 2009; 14(3):807-817.

15. Machado CV. O modelo de intervenção do Ministério da Saúde nos anos 90. Cad Saude Publica 2007; 23(9):2113-2126.

16. Levcovitz E, Lima LD, Machado CV. Política de saúde nos anos 90: relações intergovernamentais e papel das normas operacionais básicas. Cien Saude Colet 2001; 6(2):269-291.

17. Viana ALD, Lima LD, Oliveira RG. Descentralização e federalismo: a política de saúde em novo contexto - lições do caso brasileiro. Cien Saude Colet 2002; 7(3):493-507.

18. Brasil. Portaria GM/M S n.399, de 22 de fevereiro de 2006. Diário Oficial da União 2006; 23 fev.

19. Brasil. Portaria GM/M S n.699, de 30 de março de 2006. Diário Oficial da União 2006; 03 abr. 
20. Brasil. Portaria GM/M S n. 204, de 29 de janeiro de 2007. Diário Oficial da U nião 2007; 31 jan.

21. Brasil. M inistério da Saúde. Regionalização solidária e cooperativa: orientações para sua implementação no SUS. Brasília: M inistério da Saúde; 2006. (Série Pactos pela Saúde, v. 3)

22. Brasil. Ministério da Saúde. Colegiado de Gestão Regional na região de saúde intra-estadual: orientações para organização e funcionamento. Brasília: M inistério da Saúde; 2009. (Série Pactos pela Saúde, v. 10)

23. Souza C. Políticas públicas: uma revisão da literatura. Sociologias 2006; 8(16):20-45.

24. Ham C, Hill M. The Policy Process in the Modern Capitalist State. H ertfordshire: H averster Wheatsheaf; 1993.

25. Thelen K, Steinmo S, editors. Structuring Politics. Historical Institucionalism in Comparative Analysis. Cambridge: Cambridge U niversity Press; 1992.

26. Hall P, Taylor RCR. As três versões do neo-institucionalismo. Lua Nova 2003; 58:193-223.

27. Pierson P. Politics in time. Princeton: Princeton University Press; 2004.

28. Deslandes SF, Gomes R. A pesquisa qualitativa nos serviços de saúde: notas teóricas. In: Bosi MLM, M ercado FJ, organizadores. Pesquisa qualitativa de serviços de saúde. Rio de Janeiro: Editora Vozes; 2004. p. 99-120.

29. M inayo MCS. 0 desafio do conhecimento: pesquisa qualitativa em saúde. São Paulo: Editora Hucitec; 2006.

30. Brasil. M inistério da Saúde. Secretaria Técnica da Comissão Intergestores Tripartite. Brasília: M S; 2010 [Dados não publicados].

31. Brasil. M inistério da Saúde. Departamento de Apoio à Gestão Descentralizada - DAGD/SE. Brasília: MS; 2010. [Dados não publicados]

32. Machado CV, Baptista TWF, Lima LD. O planejamento nacional da política de saúde no Brasil: estratégias e instrumentos nos anos 2000 Cien Saude Colet 2010; 15(5):757-772.

33. Brasil. Portaria GM/M S n. 2751, de 11 de novembro de 2009. Diário Oficial da União 2009; 12 nov.

Artigo apresentado em 10/03/2011

Aprovado em 10/04/2011

Versão final apresentada em 20/04/2011 